\title{
A novel U2-U6 snRNA structure is necessary for mammalian mRNA splicing
}

\author{
Jing-Song Sun and James L. Manley \\ Department of Biological Sciences, Columbia University, New York, New York 10027 USA
}

\begin{abstract}
Splicing of mRNA precursors requires a complex and dynamic set of RNA-RNA base-pairing interactions in which the U2 and U6 snRNAs play central roles. Using a genetic suppression assay, we refine and extend a U2-U6 snRNA structure that may comprise the catalytic center of the spliceosome. We first show that a critical U2-U6 helix proven in yeast, helix Ia, is also essential for mammalian splicing. Mutations in the adjacent helix Ib, however, cannot be similarly suppressed, and relevant residues in both $\mathrm{U} 2$ and $\mathrm{U} 6$ are shown to participate in intramolecular, rather than intermolecular, base-pairing. We next demonstrate the requirement for a novel U2-U6 helix, helix III, which involves bases extending $3^{\prime}$ ' from the branch site recognition sequence in $U_{2}$ and $5^{\prime}$ from an evolutionarily invariant sequence in $U 6$ implicated previously in $5^{\prime}$ splice site recognition. This configuration suggests that helix III may help juxtapose the pre-mRNA 5' splice site and branch site. We provide evidence for this by demonstrating that a branch site mutation can be suppressed by a mutation in the $5^{\prime}$ splice site, provided that compensatory changes are made in the appropriate bases in U2 and U6. Our results provide new insights into how U2 and U6 snRNAs interact with each other and with the pre-mRNA to initiate the first catalytic step in splicing.
\end{abstract}

[Key Words: U2 and U6 snRNAs; mRNA splicing; RNA catalysis; hairpin ribozyme]

Received February 6, 1995; revised version accepted February 23, 1995.

Splicing of nuclear mRNA precursors is a complex process that proceeds by a reaction pathway consisting of two consecutive transesterifications (for review, see Green 1991; Moore et al. 1993). In the first, the 2' OH of an adenosine located near the $3^{\prime}$ end of the intron (the branchpoint) is activated and attacks the phosphodiester bond at the $5^{\prime}$ end of the intron, generating the $5^{\prime}$ exon containing a $3^{\prime} \mathrm{OH}$ and a circular lariat intermediate with a $2^{\prime}-5^{\prime}$ linkage between the branchpoint and conserved guanosine at the intron $5^{\prime}$ end. The second step is similar, except with the $3^{\prime}$ hydroxyl of the first exon activated to attack the phosphodiester bond at the end of the intron, producing the spliced mRNA and lariat intron. Catalysis of these two steps requires a very large (currently unknown) number of proteins and five small nuclear RNA molecules (snRNAs) that assemble into a massive structure, the spliceosome. How (and if) any of the proteins participate directly in catalysis is not known. In contrast, a clearer picture of how the snRNAs interact, both with each other and with the pre-mRNA, is rapidly emerging.

Five snRNAs, U1, U2, U4, U5, and U6, when assembled into snRNPs, are required for splicing, but only three of these are likely candidates to play a direct catalytic role (Madhani and Guthrie 1994a; for review, see Nilsen 1994). Somewhat paradoxically, U1 snRNP, which was the first snRNP shown to be necessary for splicing (see Sharp 1994), and which functions very early to help specify the $5^{\prime}$ splice site by RNA-RNA base- pairing (Zhuang and Weiner 1986; Seraphin et al. 1988; Siliciano and Guthrie 1988), now seems to be dispensable for the actual catalytic events. It appears likely that Ul snRNP dissociates from the spliceosome, with its place taken by another snRNP, U6 (Wassarman and Steitz 1992; Kandels-Lewis and Seraphin 1993; Konforti et al. 1993; Lesser and Guthrie 1993). U4 snRNA is basepaired extensively with U6 snRNA in a single snRNP (for review, see Guthrie 1991) but dissociates prior to the first step of splicing and is not required for catalysis (Lamond et al. 1988; Yean and Lin 1991). This leaves U2, U5, and U6 snRNAs, and considerable evidence now suggests that these RNAs, especially U6, function more directly in splicing. U2 snRNA is known to base-pair with the branch site sequence in the pre-mRNA, resulting in a helix from which the adenosine nucleophile is bulged (Parker et al. 1987; Wu and Manley 1989; Zhuang and Weiner 1989). Likely while bound to the branch site, U2 can make two separate base-pairing interactions with U6 snRNA. The first discovered interaction, now called helix II, was proven in mammalian systems and involves sequences at the $5^{\prime}$ end of U2 and the $3^{\prime}$ end of U6 (Datta and Weiner 1991; Wu and Manley 1991). The ability to form this helix is conserved throughout evolution, although the identities of the bases involved are not (Hausner et al. 1990), and it now seems likely that the function of this region may be to position the two RNAs to facilitate additional interaction. The second helix, helix I, was shown to be required for splicing in yeast and in- 
volves bases adjacent to critical sequences in both $\mathrm{U} 2$ and U6 (Madhani and Guthrie 1992, 1994b). Specifically, helix I involves U2 residues just $5^{\prime}$ to the branch recognition region, and $\mathrm{U} 6$ residues just $3^{\prime}$ to the evolutionarily invariant and mutationally sensitive ACAGAGA sequence (see also Fabrizio and Abelson 1990; Madhani et al. 1990; McPheeters and Abelson 1992; Wolff et al. 1994). U6 residues required for helix I are paired with U4 in the U4-U6 snRNP, so disruption of this interaction is required prior to helix I formation, which also appears to allow formation of an intramolecular stem-loop in U6 (see Fig. 1A for a depiction of documented U2-U6 interactions; Wolff and Bindereif 1993; Fortner et al. 1994).

Additional snRNA/pre-mRNA interactions have been described recently that may be directly relevant to catalysis. A conserved loop sequence in U5 snRNA has been shown, both by genetic experiments in yeast (Newman and Norman 1991, 1992) and mammals (Cortes et al 1993) and by in vitro cross-linking experiments in mammals (Wyatt et al. 1992; Sontheimer and Steitz 1993), to interact with exon sequences near both the $5^{\prime}$ and $3^{\prime}$ splice sites, perhaps helping to align the exons for proper ligation. U6 snRNA has also been shown to base-pair with sequences near the $5^{\prime}$ splice site, in this case with bases toward the $3^{\prime}$ end of the $5^{\prime}$ splice site consensus. This interaction was first suggested by cross-linking experiments (Wasserman and Steitz 1992; Sawa and Abelson 1992; Sawa and Shimura 1992; Sontheimer and Steitz 1993) and then proven by genetic suppression experiments in yeast (Kandels-Lewis and Seraphin 1993; Lesser and Guthrie 1993). The sequence in U6 involved is the invariant ACA sequence which, as mentioned above, is located just $5^{\prime}$ to U2-U6 helix I. Thus helix I, the U2/pre-mRNA branch site helix and the U6-5' splice site pairing together suggest a possible mechanism for bringing the reactants in the first step of splicing into proximity.

The existence of these dynamic RNA-RNA interactions strengthens the view that pre-mRNA splicing is RNA catalyzed (for review, see Moore et al. 1993; Weiner 1993). Indeed, similarities with several catalytic RNAs have been noted. Comparisons with group II self-splicing introns have received the most attention. The two processes were suggested to be related both evolutionarily and mechanistically, based initially on the striking observation that the structures of the reaction intermediates and products are identical (see Sharp 1985; Cech 1986). Additional structural similarities have supported this idea. Most notably, in both cases the nucleophile in the first step is the $2^{\prime} \mathrm{OH}$ of an A bulged from a helix, and immediately adjacent is a second helix that is essential for activity (U2-U6 helix I in pre-mRNA splicing and domain 5 in group II splicing; structural features of group II introns are reviewed in Michel et al. 1989). A similarity between the second step of pre-mRNA splicing and group I self-splicing has also been suggested, based both on the phenotype of specific U2 snRNA mutants (McPheeters and Abelson 1992) and stereochemical studies of splicing (Moore and Sharp 1993). Recent studies, however, have indicated that the function of the U2 bases suggested to form a group I-like structure is instead to pair with bases in U6, to form the U2-U6 helix I mentioned above (Madhani and Guthrie 1994b). Finally, it has been noted that critical sequences in U6 snRNA, including the conserved ACAGAGA and the intramolecular stem-loop, bear considerable similarity to the socalled hairpin ribozyme (Tani and Ohshima 1991). Indeed, limited mutagenesis of U6 within the hairpin region can convert it to an active hairpin-like ribozyme (Tani et al. 1992). The different chemistries of the reaction products, however $\left(2^{\prime}-3^{\prime}\right.$ cyclic phosphate and $5{ }^{\prime}$ $\mathrm{OH}$ for the ribozyme), might suggest that the two reactions are not mechanistically related.

In this paper we describe experiments designed to investigate further the interactions between $\mathrm{U} 2$ and U6 snRNAs and the pre-mRNA. Using a cotransfection assay described previously, we present genetic evidence for several U2-U6 interactions, most notably a third intramolecular helix, helix III. By analyzing mutations in the pre-mRNA, we provide evidence that U2 and U6 residues at one end of helix III interact directly with the pre-mRNA branch site and $5^{\prime}$ splice site, respectively. Our data suggest a model for catalysis of the first step of splicing that incorporates features of the hairpin ribozyme.

\section{Results}

We described previously an in vivo assay that allows us to identify functionally important residues in U2 and U6 snRNAs, and also provides a means of examining basepairing interactions between these RNAs, as well as with the pre-mRNA (Wu and Manley 1989, 1991, 1992). The assay involves cotransfection of human 293 cells with a plasmid capable of transcribing the SV40 early region to produce, by use of alternative 5 ' splice sites, the large $T$ and small $t$ mRNAs. However, by mutating the unique small $t$ branch site, small $t$ mRNA is not produced unless the cells are cotransfected with a plasmid producing a U2 snRNA with an appropriate compensatory mutation. This allows analysis of second site mutations in the suppressor U2 gene. Small $t$ splicing can also be made dependent on exogenous expression of U6 snRNA by introduction of a suppressible mutation in the U2 sequences required for U2-U6 helix II, which allows analysis of second site mutations in U6. Total cytoplasmic RNA is prepared and small $t$ and large $T$ mRN.As detected by SI nuclease analysis, and where necessary, quantitated by PhosphorImager analysis (see Materials and methods). Large $T$ splicing utilizes its own set of branchpoints and is not detectably affected by mutations in the small $t$ branch site (Noble et al. 1987, 1988). It thus serves essentially as an internal control. In the experiments described below, as well as those described previously, we have never detected reductions in large $\mathrm{T}$ mRNA as a result of expression of variant $\mathrm{U} 2$ and $\mathrm{U} 6$ snRNAs, indicating that the mutants do not function as general dominant inhibitors of splicing.

\section{Helix $I$}

The existence of U2-U6 helix I was demonstrated in 
yeast by compensatory mutations (Madhani and Guthrie $1992,1994)$. The helix was suggested to consist of two parts, helix Ia and Ib, separated by a 2-nucleotide bulge of U2 sequences (see Fig. 1A). We wished to determine whether we could obtain evidence for the existence of this helix in our assay system, for at least two reasons. First, it appears that there may be differences in the RNA requirements for splicing in yeast and mammals. For example, it now seems likely that U2-U6 helix II plays a more important role in mammalian systems than it does in yeast, whereas mutations in certain highly conserved U6 residues appear to have less severe effects in mammals than they do in yeast (Datta and Weiner 1993 and references therein). Second, although the evidence for the existence of helix Ia in yeast is compelling, that for $\mathrm{Ib}$ is less conclusive (Madhani and Guthrie 1992). Mutations in any of the three relevant $\mathrm{U} 6$ residues can cause lethality, and mutations of the residue at the base of the putative stem can be suppressed by compensatory mutations in U2. But the identity of this U2 base, as well as the adjacent one, seem unimportant in the context of wild-type U6, and mutations in the other two U6 bases cannot be suppressed. The data on helix Ib in yeast thus provide evidence for base-pairing at only one position and raise the possibility that formation of this helix may not be essential for splicing.

To investigate whether a helix I-like structure is required for splicing of a mammalian pre-mRNA, we used the transient transfection assay described above. Specifically, 293 cells were transfected with three plasmids, one expressing SV40 early pre-mRNA with a triple mutation in the small $t$ branch site (SV-AGU), one expressing human U2 snRNA with a compensatory triple mutation plus a single base mutation in sequences required for U2-U6 helix II (U2-UCA-7G), and a third expressing U6 snRNA with a compensatory mutation restoring helix II formation (U6-91C). Cells transfected with these plasmids produce wild-type levels of small $t$ mRNA that is dependent on expression of the $\mathrm{U} 2$ and $\mathrm{U} 6$ plasmids
(Fig. 2, lane 1; see also Wu and Manley 1991). Figure 2 presents the results of experiments examining the effects of mutations in residues predicted to form helix Ia (see Fig. 1B). We prepared two sets of double mutants in which the bases at the center of the helix were mutated. In both $U 2$ and $U 6$, the relevant bases (U2-26A, 27U, and U6-50A, 51U) were changed to either CC or GG. When these plasmids were used in transfections in place of the appropriate U2 (or U6) plasmid mentioned above, small t splicing was abolished (Fig. 2, lanes 2,3,5,6), indicating that one or both of the mutated bases is essential for U2 (or U6) function. To determine whether that function was base-pairing to form helix Ia, the plasmids were used in pairs that would allow the predicted pairing to occur. The results (Fig. 2, lanes 4,7) show that efficient small $t$ splicing was restored, providing strong support for the existence of a base-pairing interaction between these two positions. This conclusion is strengthened by the allele specificity of the suppression: No restoration of small $\mathrm{t}$ splicing was observed when the U2 and $\mathrm{U} 6 \mathrm{mu}-$ tants unable to base-pair were cotransfected (Fig. 2, lanes $9,10)$. These results indicate that U2-U6 helix Ia can be required for splicing in mammalian cells.

We next wished to examine bases that would constitute helix $\mathrm{Ib}$. Two separate single-base changes were first introduced into U6-53A ( $A \rightarrow C$ or $G)$ and $U 2-22 \mathrm{U}$ $(\mathrm{U} \rightarrow \mathrm{G}$ or $\mathrm{C})$. These plasmids were then used in cotransfections, and the resulting levels of small $t$ and large $T$ mRNAs determined as above. Figure $3 \mathrm{~A}$ shows that all four mutations had, at most, minimal effects on small $t$ splicing (cf. lane 1 with lanes 2,3,5 and 6). In addition, when the mutants were used in pairs that would allow the restoration of base-pairing (lanes 4,7), no significant increases in small t splicing were detected. (PhosphorImager analysis verified that the small $\mathrm{t} /$ large $\mathrm{T}$ mRNA ratios were only slightly reduced $(10 \%-30 \%)$ by all of the mutations tested and that the mutant combinations did not significantly increase the ratios.) These results indicate that base-pairing at this position is not required for
A

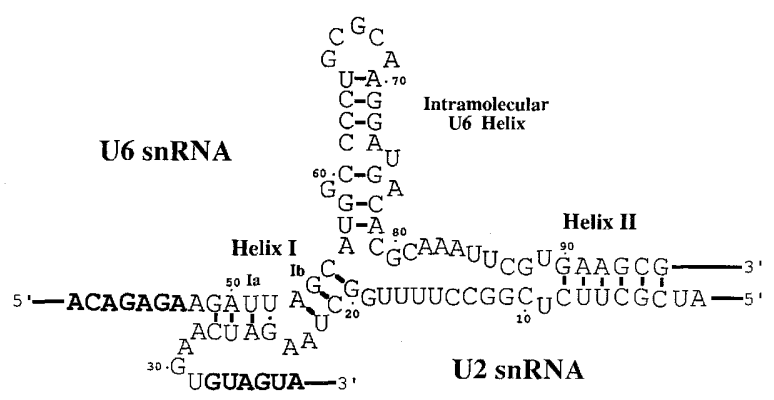

B

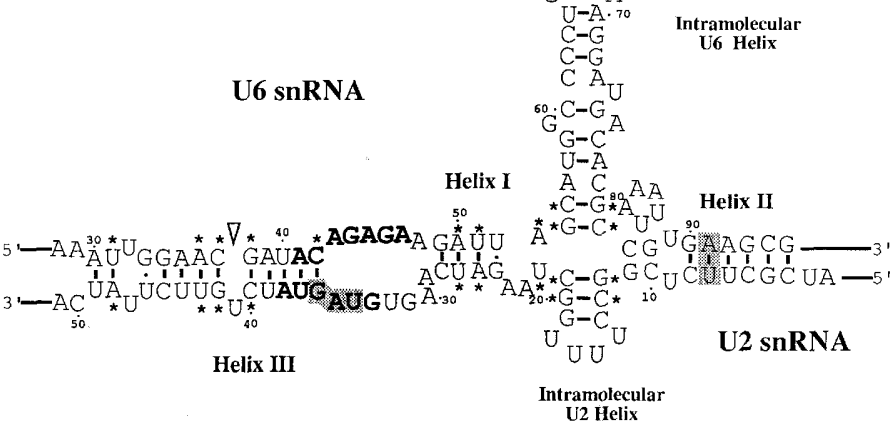

Figure 1. U2-U6 snRNA structures. Regions of human U2 and U6 suggested previously $(A)$ or hypothesized here $(B)$ to participate in intramolcular and/or intermolecular base-pairing are shown. The numbers indicate position relative to the RNA 5 ' end. The invariant ACAGAGA sequence in $\mathrm{U} 6$ and the branch site recognition sequence in $\mathrm{U} 2$ are in boldface type. In $B$, the asterisks indicate positions mutated in the current study. The open arrowhead indicates the position of a single-base insertion. The shading indicates bases mutated in U2-UCA, U2-UCA-7G, or U6-91C. 


\begin{tabular}{|c|c|c|c|c|c|c|c|c|c|c|}
\hline Lane: & 1 & 2 & 3 & 4 & 5 & 6 & 7 & 8 & 9 & 10 \\
\hline U2: & $7 G$ & $7 G$ & $\begin{array}{c}26,27 \mathrm{CC} \\
.7 \mathrm{G}\end{array}$ & $\begin{array}{c}26,27 \mathrm{CO} \\
-7 \mathrm{G}\end{array}$ & $7 G$ & $\begin{array}{c}26,27 \mathrm{GG} \\
-7 \mathrm{G}\end{array}$ & $\begin{array}{c}26,27 \mathrm{GG} \\
-7 \mathrm{G}\end{array}$ & $7 G$ & $\begin{array}{c}26,27 \mathrm{CC} \\
-7 \mathrm{G}\end{array}$ & $\begin{array}{c}26,27 \mathrm{GG} \\
-7 \mathrm{G}\end{array}$ \\
\hline U6: & $91 \mathrm{C}$ & $\begin{array}{c}50,51 \mathrm{GG} \\
.91 \mathrm{C}\end{array}$ & $91 \mathrm{C}$ & $\begin{array}{c}50,51 \mathrm{GG} \\
\cdot 91 \mathrm{C}\end{array}$ & $\begin{array}{c}50,51 \mathrm{CC} \\
.91 \mathrm{C}\end{array}$ & $91 \mathrm{C}$ & $\begin{array}{c}50,51 \mathrm{CC} \\
-91 \mathrm{C}\end{array}$ & $91 \mathrm{C}$ & $\left|\begin{array}{c}50,51 \mathrm{CC} \\
-91 \mathrm{C}\end{array}\right|$ & $\begin{array}{c}50,51 \mathrm{GG} \\
-91 \mathrm{C}\end{array}$ \\
\hline
\end{tabular}

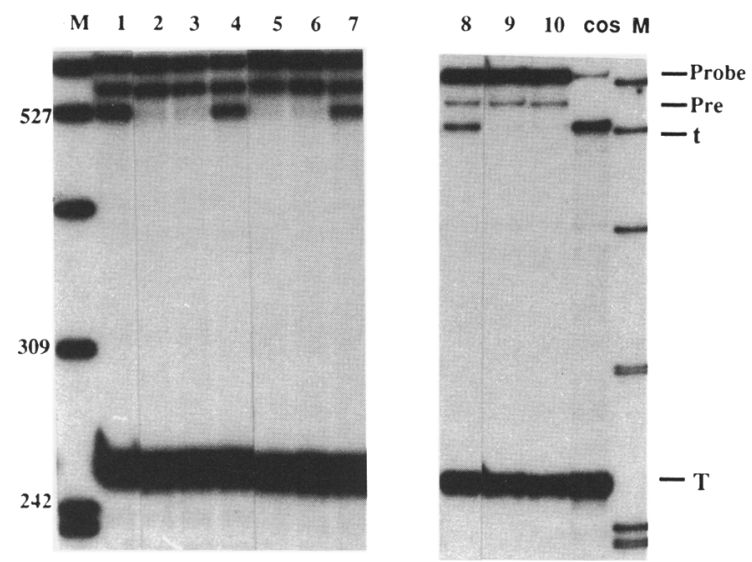

Figure 2. Demonstration of human U2-U6 helix Ia by genetic suppression. Human 293 cells were cotransfected with the SV40 early region expression vector SV-AGU and the indicated U2 and $\mathrm{U} 6$ plasmids. Mutations were constructed in either U2UCA-7G or U6-91C. Cells were harvested, RNA was extracted, and SV40 large $T$ and small $t$ mRNAs detected by S1 nuclease analysis and gel electrophoresis as described in Materials and methods. The positions of S1-protected fragments corresponding to large T mRNA $(T)$, small $t$ mRNA $(t)$, precursor RNA (Pre), and undigested probe (P) are indicated. (M) DNA size markers (numbers indicate size in nucleotides); (cos) Sl nuclease analysis of RNA extracted from SV40-transformed COS-7 cells.

splicing and that the identities of the two bases are not critical.

We next examined the other two positions that could conceivably participate in formation of a helix Ib-like structure. Given that the single-base mutations at the bottom of the putative stem did not significantly affect splicing, we first introduced double mutations into both U2 (positions 20,21 ) and U6 (positions 54,55 ), changing $5^{\prime}$ GC to CG in each (see Fig. 1A). Figure 3B, lanes 2 and 3 , shows that the resultant U2 and U6 snRNAs were completely inactive, suggesting that in each case one or both of the mutated bases are essential. Small $t$ splicing was also undetectable when the two mutant plasmids were transfected together, which would allow restoration of helix Ib base-pairing (lane 4), indicating that the mutated bases must play a role instead of, or in addition to, intermolecular base-pairing. In each case, an interesting alternative possible function is intramolecular basepairing. U6 residues 54 and 55 could potentially pair with residues 80 and 81 to extend the U6 intramolecular helix (see Fig. 1B), whereas U2 bases 20 and 21 could pair with bases 12 and 13 to form the top of U2 stem I. Evidence has in fact been described suggesting this latter pairing in yeast (McPheeters and Abelson 1992). We therefore introduced the appropriate compensatory mutations to allow each of these putative interactions to occur. While the U6 mutant remained inactive (Fig. 3B, lane 6 ), small $\mathrm{t}$ splicing was restored by the $\mathrm{U} 2$ derivative (lane 5). Thus, it appears that a function of $U 2$ bases 20 and 21 is to participate in formation of an intramolecular stem and that formation of U2-U6 helix Ib is not essential. However, to investigate further the possibility that the function of U6-54 and 55 might nonetheless involve pairing with U2-20, 21, we tested whether U6-54, 55 could be suppressed by the U2-20, 21-12, 13 mutant. The U6-54, 55 mutation was tested either by itself (Fig. $3 \mathrm{~B}$, lane 7) or together with the compensatory 80,81 mutation (lane 8). In neither case was small $\mathrm{t}$ splicing detected, indicating again that U6 positions 54 and/or 55 are important for $\mathrm{U} 6$ function, but failing to provide evidence that this function is formation of U2-U6 helix Ib.

To investigate further the possible role of U6 bases 54 and 55, single mutations were introduced into U6-91C at each of these positions (54G $\rightarrow$ C, 55C $\rightarrow$ G). Both of these mutations eliminated small $\mathrm{t}$ splicing (Fig. 4, lanes 2,3 ). To test whether this might be because of destabilization of the U6 intramolecular helix, compensatory mutations were introduced at U6 positions 80 and 81 . These mutations were tested first in the context of wild type at positions 54 and 55 . U6-80C reduced small $t$ splicing only slightly (Fig. 4, lane 4), whereas U6-81G had a more significant effect, although small $t$ splicing was still detectable (lane 5). However, when the mutations were combined so as to restore the potential for base-pairing (i.e., $54 \mathrm{C}+81 \mathrm{G}$ and $55 \mathrm{G}+80 \mathrm{C}$ ), very efficient small $\mathrm{t}$ splicing was detected in each case (lanes $6,7)$. It is noteworthy that while the single mutations at positions 54 and 55 were efficiently suppressed, the corresponding double mutation was not. This may reflect a more serious perturbation of an alternative structure, such as the U4-U6 helix, by the latter. In any event, our results indicate that $\mathrm{U} 6$ bases 54 and 55 participate in intramolecular base-pairing, with residues 81 and 80 , respectively, thereby extending and strengthening the U6 intramolecular helix.

\section{Helix III}

The region just $3^{\prime}$ to the branch recognition site in U2 snRNA (residues 39-49) is of interest for several reasons. First, much of the region (residues 40-47) is phylogenetically invariant, suggestive of an important function (Guthrie and Patterson 1988). Second, we showed previously that single-base changes in this region eliminated splicing or greatly reduced it (Wu and Manley 1992). Third, Takahashi et al. (1993) suggested the possibility that these bases might pair with bases in U6 snRNA that lie just $5^{\prime}$ to the invariant ACAGAGA sequence. We therefore attempted to determine whether or not this structure, which we call helix III, actually exists. To this end, we first tested whether three of the mutations in U2 that we analyzed previously $(43 \mathrm{U} \rightarrow \mathrm{C}, 42 \mathrm{G} \rightarrow \mathrm{A}$, and $40 \mathrm{C} \rightarrow \mathrm{G}$; see Fig. 1B/ could be suppressed by the appropriate compensatory mutations in U6. [These U2 muta- 
A

\begin{tabular}{r|c|c|c|c|c|c|c|} 
Lane: & 1 & 2 & 3 & 4 & 5 & 6 & 7 \\
\cline { 2 - 8 } U2: & $7 G$ & $7 G$ & $22 \mathrm{C}-7 \mathrm{G}$ & $22 \mathrm{C}-7 \mathrm{G}$ & $7 \mathrm{G}$ & $22 \mathrm{G}-7 \mathrm{G}$ & $22 \mathrm{G}-7 \mathrm{G}$ \\
\hline
\end{tabular}

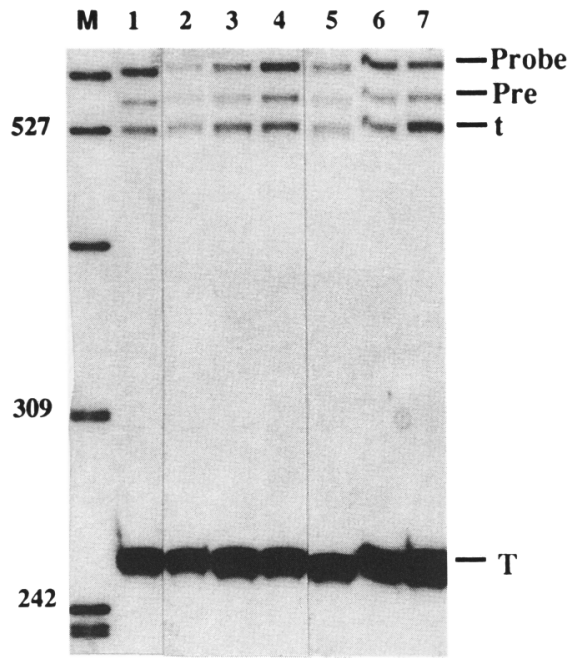

B

\begin{tabular}{|c|c|c|c|c|c|c|c|c|}
\hline Lane: & 1 & 2 & 3 & 4 & 5 & 6 & 7 & 8 \\
\hline U2: & $7 G$ & $\begin{array}{c}20,21 \mathrm{CG} \\
-7 \mathrm{G}\end{array}$ & $7 G$ & $\begin{array}{c}20,21 \mathrm{CG} \\
-7 \mathrm{G}\end{array}$ & $\begin{array}{c}12,13 \mathrm{CG} \\
20,211 \mathrm{CG} \\
-7 \mathrm{G}\end{array}$ & $7 G$ & $\begin{array}{c}12,13 \mathrm{CG} \\
20,21 \mathrm{CG} \\
-7 \mathrm{FG}\end{array}$ & $\begin{array}{c}12,13 \mathrm{CG} \\
20,21 \mathrm{CG} \\
-7 \mathrm{G}\end{array}$ \\
\hline U6: & $91 \mathrm{C}$ & $91 C$ & $\begin{array}{c}54,55 \mathrm{CG} \\
-91 \mathrm{C}\end{array}$ & $\begin{array}{c}54,55 \mathrm{CG} \\
-91 \mathrm{C}\end{array}$ & $91 \mathrm{C}$ & $\begin{array}{c}54,55 \mathrm{CG} \\
80,81 \mathrm{CG} \\
-91 \mathrm{C}\end{array}$ & \begin{tabular}{|c}
$54,55 \mathrm{CG}$ \\
$-91 \mathrm{C}$
\end{tabular} & $\begin{array}{c}54,55 \mathrm{CG} \\
80,81 \mathrm{CG} \\
-91 \mathrm{C}\end{array}$ \\
\hline
\end{tabular}

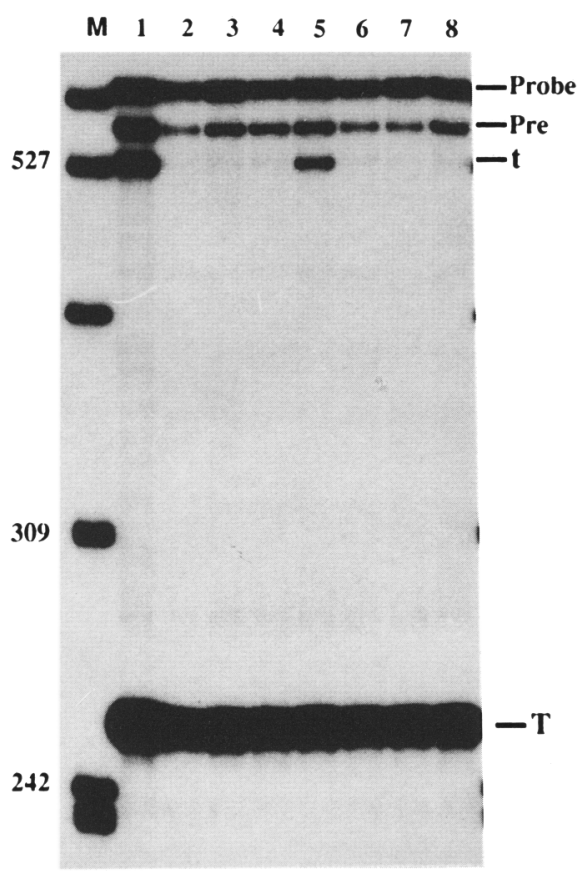

Figure 3. Effects on splicing of mutations in U2-U6 helix Ib. The indicated U2 and U6 mutants, constructed in U2-UCA-91G or U6-91C, were cotransfected with SV-AGU and analyzed exactly as described in the legend to Fig. 2. (A) U2 position 22 and U6 position 53 are not essential for splicing. (B) The indicated double mutations, at U2 positions 20, 21, and/or 12, 13 and U6 positions 54,55 , and/or 80, 81, all prevent splicing and provide evidence for a required U2 intramolecular helix.

tions were introduced into U2-UCA rather than U2UCA-7G (Wu and Manley 1992)]. The compensatory U6 mutations were therefore made in wild-type U6. This has the advantage of simplifying the analysis somewhat but the disadvantage that the effects of the U6 mutations cannot in principle (although see below) be tested independently, as function of the exogenous U6 is not demanded by the assay.)

The results of cotransfections are shown in Figure 5A. As observed previously, each of the three U2 mutations greatly reduced or eliminated small $\mathrm{t}$ splicing (lanes $2,5,8$ ). Unexpectedly, each of the three U6 plasmids, when transfected with the parental U2-UCA, resulted in reductions in small $\mathrm{t}$ splicing (lanes 3,6 and 9; cf. with lane 1). Although this inhibition was variable and not always observed (results not shown), it suggests that the mutant U6 snRNAs can exert a dominant-negative effect on small $t$ splicing. Large $T$ splicing was unaffected, suggesting that the inhibition was limited to small $t$. This likely reflects the fact that small $t$ splicing is more easily perturbed, perhaps because of its limiting size (e.g., Fu et al. 1988|. Most significantly, however, when the U2 mutants were cotransfected with the appropriate compensatory U6 mutant, small $\mathrm{t}$ splicing was in each case very efficiently restored (lanes $4,7,10)$, providing evidence for U2-U6 base-pairing at these positions. Suppression was again allele specific: When the U2 mutants were cotransfected with a U6 derivative containing a noncompensatory mutation, no small $\mathrm{t}$ splicing could be detected (Fig. 6). Together, these results provide strong evidence for the existence of a third U2-U6 helix, helix III.

We extended our analysis of helix III to include two additional positions. For this, mutations were introduced into U2-UCA-7G and U6-91C, to allow determination of the effects of the U6 mutations. First, the potential for base-pairing is rather extensive (see Fig. 1B), and we wished to determine whether pairing at a distal position is essential for splicing. Single-base changes were therefore made at $U 2$ position $48(\mathrm{~A} \rightarrow \mathrm{U})$ and $\mathrm{U} 6$ position $31(\mathrm{U} \rightarrow \mathrm{A})$. Second, the potential to form helix III is evolutionarily conserved, despite the fact that there is some variation in the residues involved, especially in 


\begin{tabular}{|c|c|c|c|c|c|c|c|}
\hline Lane: & 1 & 2 & 3 & 4 & 5 & 6 & 7 \\
\hline U2: & 70 & 76 & $7 G$ & $7 G$ & $7 G$ & $7 G$ & 76 \\
\hline U6: & 91C & $\begin{array}{l}54 \mathrm{C} \\
-91 \mathrm{C}\end{array}$ & $\begin{array}{l}55 G \\
.91 C\end{array}$ & $\begin{array}{l}80 C \\
.91 C\end{array}$ & $\begin{array}{r}81 G \\
.91 C\end{array}$ & $\begin{array}{c}54 \mathrm{C}, 81 \mathrm{G} \\
-91 \mathrm{C}\end{array}$ & $\begin{array}{c}55 G, 800 \\
.91 C\end{array}$ \\
\hline
\end{tabular}

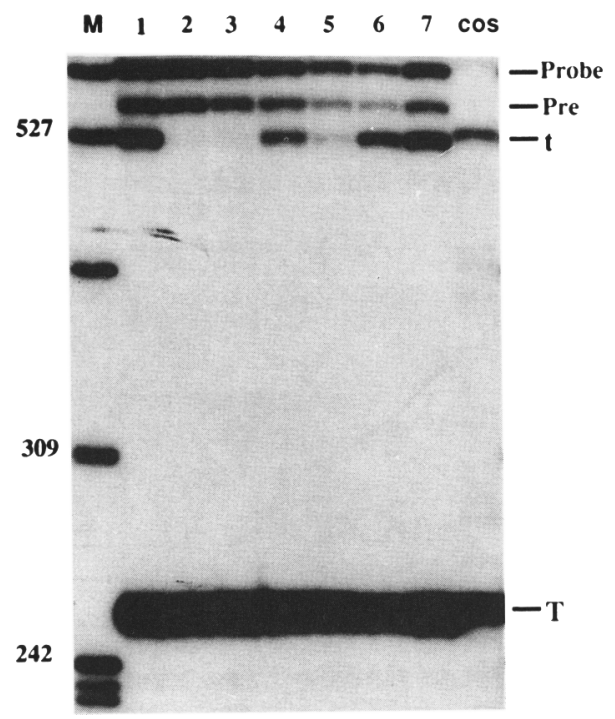

Figure 4. U6 snRNA bases in putative helix Ib participate in intramolecular base pairing. The indicated single-base substitution mutations in U6, at positions 54 or 55 and/or 80 or 81 , were analyzed exactly as described in the legend to Fig. 2. The U6 mutants, all in the U6-91C vector, were cotransfected with U2-UCA-7G plus SV-AGU.

U6 (Takahashi et al. 1993). However, in all species at least one bulge in the helix is predicted, and we wished to test whether such a bulge is essential. In humans, U2-41U is bulged, and we therefore created a U6 mutant in which an A is inserted between residues 37 and 38, which would allow incorporation of U2-41U into the helix. The effects of these mutations on small $t$ splicing were tested, and the results are shown in Figure 5B. Mutation of either U2-48A or U6-31U essentially eliminated small t splicing (lanes 2,3 ), whereas cotransfection of the two mutant plasmids together restored splicing (lane 4). Base-pairing at this position thus appears to be required for efficient small $\mathrm{t}$ splicing, suggesting an extended structure for helix III. In contrast, the U6 insertion mutant retained full activity (lane 5), indicating that the $U$ at position 41 in $U 2$ need not be bulged.

Base-pairing between possible helix III residues and the pre-mRNA helps align the $5^{\prime}$ splice site and branch site

An intriguing feature of helix III is that bases in both U2 and U6 that constitute the right end of the helix, as it is depicted in Figure 1B, have been implicated in pairing with conserved residues in the pre-mRNA. U2 bases 36-
38 (GUA) have been proven (or strongly suggested) to pair with UAC in the pre-mRNA branch site (although the middle $A$ is not conserved, so pairing at this position may be less important), and in yeast the equivalent of U6 bases $41-42$ (AC) have been shown to pair with $\mathrm{GU}$ at positions +5 and +6 in the pre-mRNA $5^{\prime}$ splice site consensus (see introductory section for reference citations). This raises the possibility that these bases in U2 and U6 may participate in alternative base-pairing interactions and, by so doing, provide a mechanism by which the reactants in the first step of splicing / the branchpoint and 5 ' splice site) are directly juxtaposed. The following experiment provides evidence in support of this mechanism.

The SV40 plasmid used in these and previous experiments (SV-AGU) contains the triple base substitution $\mathrm{CUA} \rightarrow \mathrm{AGU}$ in the small $\mathrm{t}$ branch site, and the resulting defect in small $t$ splicing is suppressed very efficiently by the cognate U2 suppressor, U2-UCA. In contrast, a very similar mutation in the branch site, CUA $\rightarrow$ GGU, was suppressed only poorly by its cognate suppressor U2-CCA (mutated bases in the U2 suppressors are indicated $3^{\prime} \rightarrow 5^{\prime}$; Wu and Manley 1989). Although the reason for this was unclear, we speculated previously that it might be because two consecutive G-C pairs interfere with another function of $\mathrm{U} 2$ or the branch site, and it is now conceivable that this could be helix III formation and/or an interaction involving the $5^{\prime}$ splice site. To test this, we first cotransfected SV-GGU and U2-CCA together with either U6 wild type or U6-42G. [Note that only one of the three residues mutated in U2-CCA (the $3^{\prime} \mathrm{C}$; residue $36 \mathrm{G}$ in wild type) would be involved in $\mathrm{U} 6$ pairing, with $\mathrm{U} 6-42 \mathrm{C}$; see Fig. 1B.] The results (Fig. 7, lanes 2,3 ) show that in both cases small $t$ splicing was barely detectable, indicating that restoration of base-pairing between $\mathrm{U} 2$ position 36 and U6 position 42 was not sufficient to allow small $\mathrm{t}$ splicing.

The inability of U6-42G to restore splicing allowed us to test the possibility that this might reflect a defective interaction between U6 and the pre-mRNA 5' splice site. We therefore introduced an $\mathrm{A} \rightarrow \mathrm{C}$ change at position +5 in the small $t 5^{\prime}$ splice site of SV-GGU. Strikingly, when this plasmid (SV-GGU-5C) was cotransfected with U2-CCA and U6-42G, a significant amount of small $t$ mRNA was detected (Fig. 7, lane 4). Small t splicing was not detected when U6-42G was replaced with U6 wild type (lane 5) or another U6 allele, U6-42U (results not shown), providing strong evidence that G-C pairing between $U 6$ and the 5 ' splice site was required to rescue small $\mathrm{t}$ splicing. Small $\mathrm{t}$ splicing was also barely detectable when U2-CCA was replaced with U2-UCA (lane 6). U2-UCA replaces two possible G-C pairs (involving the branch site and/or U6) with G-U wobble pairs, and it is likely that one (or the combination of both) of the weaker interactions prevents suppression of the small $t$ splicing defect by the pre-mRNA $+5 \mathrm{~A} \rightarrow \mathrm{C}$ mutation. In any event, our results indicate that a branch site mutation can in effect be suppressed by a $5^{\prime}$ splice site mutation, provided a proper network of U2-U6 interactions is in place. In addition, they implicate U2-U6 
A

\begin{tabular}{|c|c|c|c|c|c|c|c|c|c|c|}
\hline Lane: & 1 & 2 & 3 & 4 & 5 & 6 & 7 & 8 & 9 & 10 \\
\hline U2: & UCA & $43 \mathrm{C}$ & UCA & $43 C$ & $42 A$ & UCA & $42 A$ & $40 G$ & UCA & $40 G$ \\
\hline U6 & WT & WT & $36 \mathrm{G}$ & $36 \mathrm{G}$ & WT & $37 U$ & $37 U$ & WT & $38 \mathrm{C}$ & $38 \mathrm{C}$ \\
\hline
\end{tabular}

B

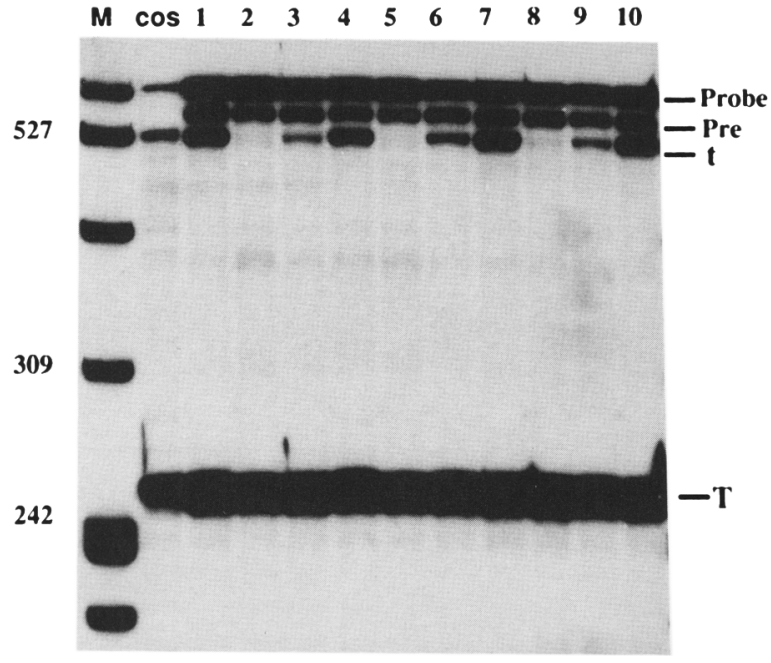

\begin{tabular}{c|c|c|c|c|c|} 
Lane: & 1 & 2 & 3 & 4 & 5 \\
\cline { 2 - 6 } U2: & $7 G$ & $\begin{array}{c}48 U \\
-7 G\end{array}$ & $7 G$ & $\begin{array}{c}48 U \\
-7 G\end{array}$ & $\begin{array}{c}\text { InsA } \\
-7 G\end{array}$ \\
\cline { 2 - 6 } U6: & $91 C$ & $91 C$ & $\begin{array}{l}31 A \\
-91 C\end{array}$ & $\begin{array}{c}31 A \\
-91 C\end{array}$ & $91 C$ \\
\hline
\end{tabular}

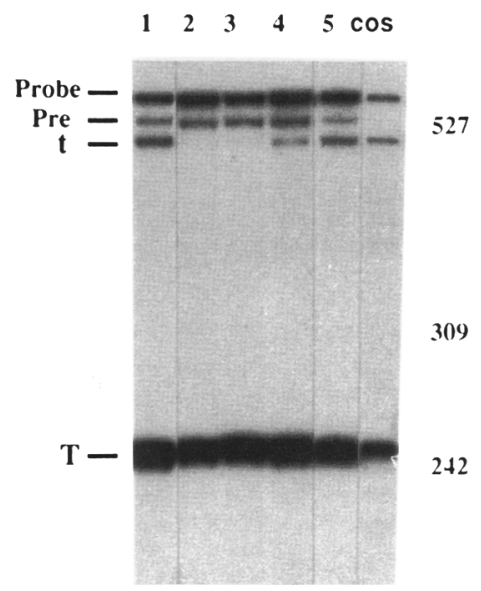

Figure 5. Compensatory U2-U6 mutations define a novel U2-U6 helix, helix III. Transfections and RNA analysis were performed exactly as in Fig. 2. In $A$, the indicated mutations were constructed in U2-UCA or U6 wild type; in $B$ the mutations were introduced into U2-UCA-7G and U6-91G.

helix III in helping to align precisely the $5^{\prime}$ splice site and branchpoint.

\section{Discussion}

The data presented here suggest a novel U2-U6 snRNA structure that likely plays an important role in catalyzing pre-mRNA splicing. The structure that we propose (Fig. 8A) incorporates features suggested previously by others (e.g., Madhani and Guthrie 1992; Takahashi et al. 1993; Fortner et al. 1994), although there are important differences. For example, the previously noted similarity with the hairpin ribozyme (Tani and Ohshima 1991) is strengthened, whereas our structure seems less related to the domain 5-6 structure of group II self-splicing introns than do previous models. We discuss below some of the details of this structure and its possible implications for the mechanism of splicing catalysis. But first we compare our findings with previous studies examining the structure and function of $\mathrm{U} 2$ and $\mathrm{U} 6$ snRNAs, paying particular attention to the residues that constitute helix III.

The effects of mutations in many of the bases in both U2 and U6 that would form helix III in yeast have been tested in in vitro and/or in vivo assays. Single-base mutations in $\mathrm{U} 2$ residues in this region, which are almost all invariant in evolution, were tested in an in vitro splicing assay (McPheeters and Abelson 1992). Although none of the mutations completely eliminated splicing, most had an effect ranging from modest to severe. These results are consistent with a role for this region in splicing and are similar to the effects observed in this assay with mutations in other important regions of U2 (e.g., helix I). The U6 bases that would form helix III have been studied more extensively. In an in vitro assay similar to that mentioned above, single-base mutations in the relevant U6 bases were all found to be without significant effect (Fabrizio and Abelson 1990). An exception was the $3^{\prime} \mathrm{AC}$ (which is part of the invariant ACAGAGA box), where mutations significantly affected splicing, although this likely reflects the documented interaction of these bases with the $5^{\prime}$ splice site (Kandels-Lewis and Seraphin 1993; Lesser and Guthrie 1993). A genetic screen designed to identify U6 mutations that affected cell viability also failed to detect effects at many positions that would constitute helix III (Madhani et al. 1990; see also Lesser and Guthrie 1993). Support for helix III in yeast, however, is provided by two genetic screens designed to detect suppressors of cold-sensitive mutations in $\mathrm{U} 4$ and $\mathrm{U} 6$ snRNAs that had the effect of destabilizing the U4-U6 snRNA interaction (Shannon and Guthrie 1991; Fortner et al. 1994). The rationale for 


\begin{tabular}{|c|c|c|c|c|c|c|c|c|c|c|}
\hline Lane: & 1 & 2 & 3 & 4 & 5 & 6 & 7 & 8 & 9 & 10 \\
\hline U2: & UCA & $43 C$ & $42 A$ & $40 G$ & $42 \mathrm{~A}$ & $43 C$ & $40 G$ & 40G & $43 C$ & $42 \mathrm{~A}$ \\
\hline U6: & WT & $36 \mathrm{G}$ & $36 \mathrm{G}$ & $36 \mathrm{G}$ & $37 \mathrm{U}$ & $37 U$ & $37 \mathrm{U}$ & $38 \mathrm{C}$ & $38 \mathrm{C}$ & $38 \mathrm{C}$ \\
\hline
\end{tabular}

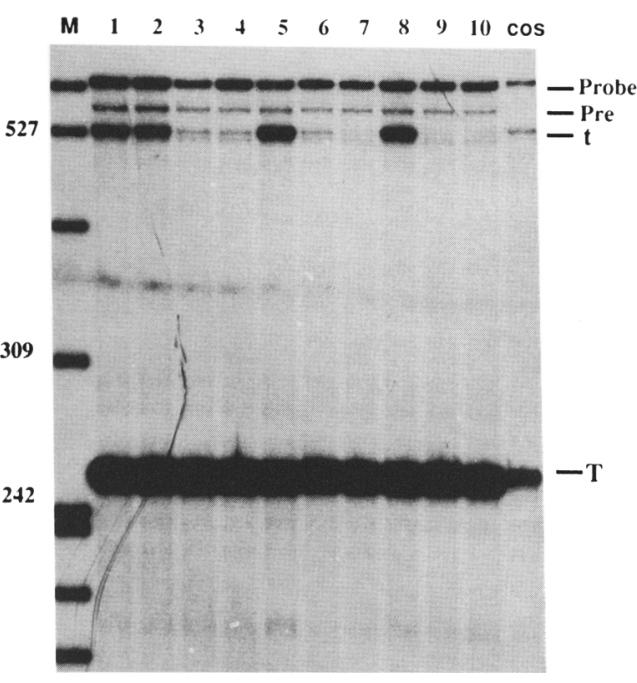

Figure 6. Suppression in U2-U6 helix III is allele specific. The indicated combinations of U2 and U6 plasmids were cotransfected with SV-AGU and analyzed exactly as in Figs. 2 and 5.

these screens was that mutations that destabilize possible competing or alternative structures might suppress the cold sensitivity. Intriguingly, a number of the suppressor mutations isolated were in U6 bases that would destabilize helix III. Similar mutations were found in U6 bases that participate in U2-U6 helices I and II, as well as in the U6 intramolecular helix. Given that all of the suppressor mutations can be explained in terms of altering RNA helices, these results both provide support for the existence of helix III in yeast and highlight the dynamic and complex set of base-pairing interactions that must occur during the spliceosome cycle. For example, if destabilization of a U2-U6 helix can in fact compensate for a weakened U4-U6 interaction, this may suggest that a function of the latter base-pairing is to destabilize the former following the completion of splicing.

Previous studies in metazoans have also addressed the requirement for U2-U6 helix III bases, although the only study on U2 was our previous analysis, which showed that single-base changes at each of five positions reduced or eliminated splicing in vivo (Wu and Manley 1992). Relevant U6 bases have been analyzed in several studies in addition to the current one. Reconstitution experiments with microinjected frog oocytes revealed that a 3 -base substitution in relevant U6 bases reduced but did not eliminate splicing (Vankan et al. 1992), although this mutation fortuitously did not have a strong destabilizing effect on helix III formation. In an in vitro reconstitution assay, a deletion removing the $5^{\prime} 23$ bases of U6 was without effect on splicing, whereas a deletion of the $5^{\prime} 33$ bases, which impinges on helix III, eliminated splicing (Wolff and Bindereiff 1992). However, subsequent studies by these investigators examining contiguous 3-base substitutions covering the helix III region failed to reveal significant effects on splicing (Wolff et al. 1994).

Several biochemical observations also support, at least indirectly, the importance of helix III. Multiple introns have been detected in the U6 gene (Tani and Ohshima 1989, 1991) and a single intron in the U2 gene (Takahashi et al. 1993) of certain yeast species. The idea that these introns arose by errors during splicing in which excised introns were inserted into the snRNA at sites near the catalytic center of the spliceosome (Brow and Guthrie 1989) continues to provide an attractive explanation for the origin of these introns. It is thus intriguing that one of the U6 introns and the sole U2 intron are present at positions that correspond to the left end of helix III (see Fig. 8A). A likely related finding that also draws attention to these bases in U6 resulted from in

\begin{tabular}{c|c|c|c|c|c|c|} 
Lane: & 1 & 2 & 3 & 4 & 5 & 6 \\
\cline { 2 - 7 } SV40: & AGU & GGU & GGU & $\begin{array}{c}\text { GGU } \\
-5 C\end{array}$ & $\begin{array}{c}\text { GGU } \\
-5 C\end{array}$ & $\begin{array}{c}\text { GGU } \\
-5 C\end{array}$ \\
\cline { 2 - 7 } U2: & $\begin{array}{l}\text { UCA } \\
-7 G\end{array}$ & CCA & CCA & CCA & CCA & UCA \\
\cline { 2 - 7 } U6: & $91 C$ & WT & $42 G$ & $42 G$ & WT & $42 G$ \\
\hline
\end{tabular}

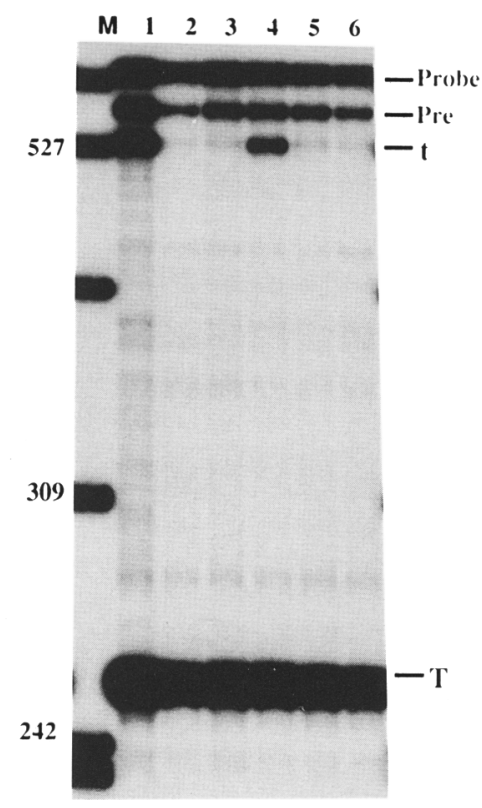

Figure 7. Suppression of a pre-mRNA branch site mutation by a $5^{\prime}$ splice site mutation through compensatory changes in U2 and U6 snRNAs. 293 cells were cotransfected with the indicated plasmids, and RNA was extracted and analyzed exactly as in Fig. 2. In addition to SV-AGU, the SV40 expression plasmids SV-GGU and SV-GGU-5C were used. In addition to the GGU substitution in the branch site, the latter contains an $\mathrm{A} \rightarrow \mathrm{C}$ mutation at position +5 in the small $t$ intron. The U6 plasmid U6-C42G contains only the single-base change at position 42 . 
A

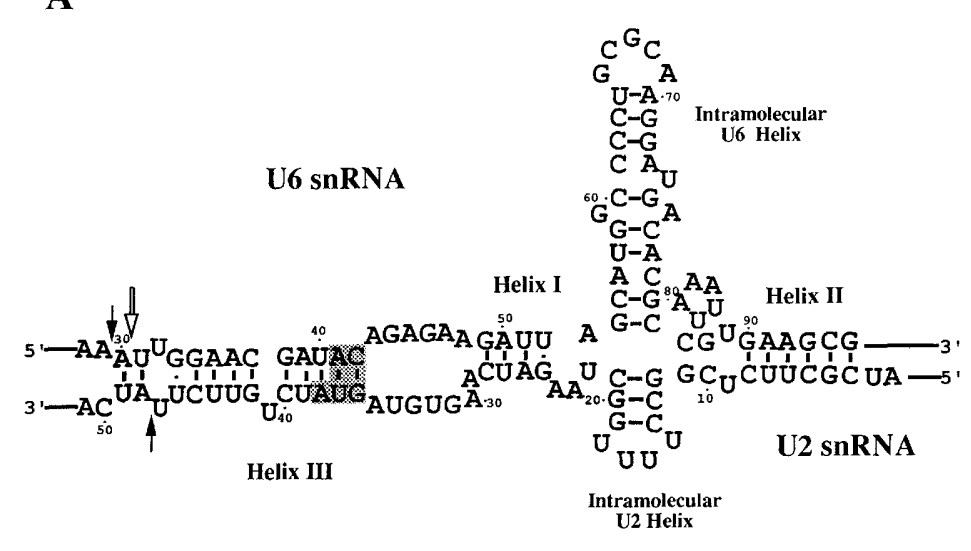

B

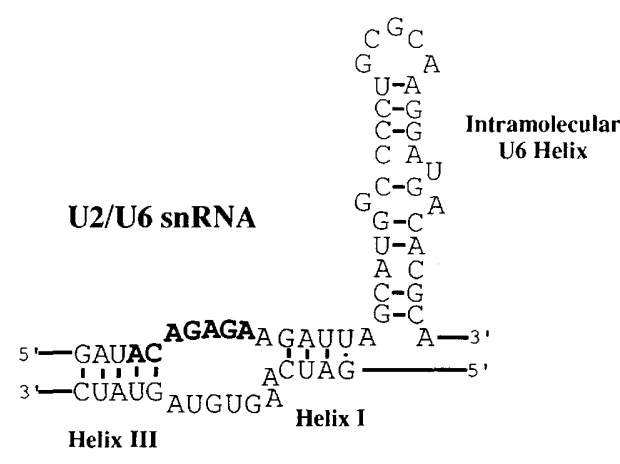

C

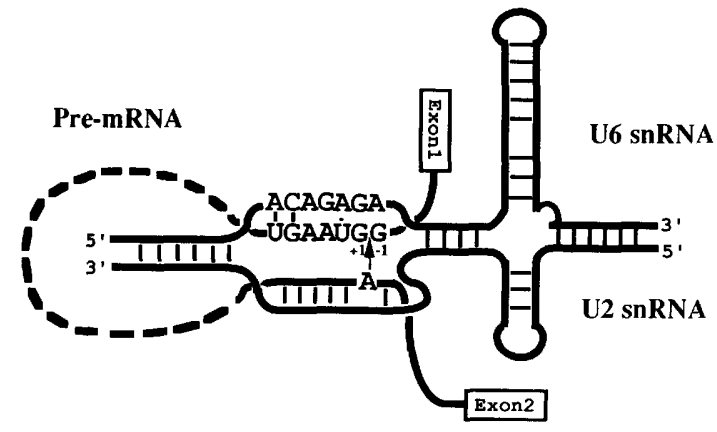

Figure 8. U2-U6 snRNA secondary structure: its relationship to the hairpin ribozyme and the first step of splicing. $(A)$ Secondary structure model of U2-U6 snRNAs. Three U2-U6 intermolecular helices and two intramolecular stem-loops are shown. In the U6 intramolecular helix, two possible A-C pairs are incorporated into the helix (see Fortner et al. 1994). However, the lack of a dash or dot indicates that their status is ambiguous. Likewise, evidence that two possible G-C pairs at the left end of helix II may not be required (Wolff and Bindereif 1992) is reflected by the absence of dashes. Note that the two intramolecular helices are juxtaposed in a manner suggesting that the structure may be stabilized by coaxial stacking.

Bases indicated by shading at the right end of helix III base-pair with the pre-mRNA instead of or in addition to each other (see text). The solid arrows indicate the positions of introns in certain fungal U2 and U6 snRNAs; the open arrow indicates the site of aberrant branch formation in reconstituted nematode splicing extracts (see text for references). (B) Comparison of U2/U6 snRNA sequences and the hairpin ribozyme. The region of the U2-U6 snRNA structure that resembles the hairpin ribozyme is shown. The invariant ACAGAGA sequences are indicated in boldface type. The arrow indicates the site of cleavage by the ribozyme, in which the $2^{\prime} \mathrm{OH}$ of the indicated adenosine is the nucleophile. $|C|$ A model for a U2-U6-pre-mRNA structure and catalysis of the first step of splicing. The diagram incorporates the pre-mRNA into the U2-U6 structure detailed in A. The bases shown are the ACAGAGA sequence in U6 and the mammalian $5^{\prime}$ splice site consensus in the pre-mRNA. The bulged branchpoint adenosine in the U2-branch site helix is also indicated. Intron sequences between the branch site and $5^{\prime}$ splice site are represented by the broken line. $(+1)$ The first base of the intron; $(-1)$ the last base in exon 1 . The arrow indicates the site of cleavage, in which the $2^{\prime} \mathrm{OH}$ of the branchpoint adenosine is the nucleophile. The A-U pair involving position +2 of the intron has been shown by chemical cross-linking, although the interaction may occur only following $5^{\prime}$ splice site cleavage (Sontheimer and Steitz 1993).

vitro splicing reconstitution experiments with nematode extracts (Yu et al. 1993). In reactions reconstituted with wild-type U6 snRNA, a low level of branch formation was detected between the splicing substrate and U6 snRNA at the AU sequence at the end of helix III (nucleotides $30-31$ in Fig. 8A). When those residues were mutated (AAUU $\rightarrow$ UUAA), a high level of aberrant branch formation was detected, now to the adjacent GG sequence. Thus, these sequences in U6 appear to function similarly to $5^{\prime}$ splice sites, despite the fact that they bear no resemblance to the consensus. As noted by the investigators, these results suggest that the natural function of these bases may be to in some way align the premRNA 5' splice site in the catalytic center. Our results, especially the strong effect of the U6-U31A mutation and its suppression by $\mathrm{U} 2-\mathrm{A} 48 \mathrm{U}$, provide evidence that this function is mediated by U2-U6 helix III.

Taken together, the results discussed above provide support for the idea that helix III plays an important role in splicing. However, it is also clear that the full-length helix is not essential in many situations, as mutations that would destabilize it can be tolerated. The fact that we were able to observe strong effects of single-base substitutions in both U2 and U6 likely reflects the exceptional sensitivity of our assay. Although this has been discussed previously (e.g., Wu and Manley 1992), one undoubtedly important feature is the limiting size of the small $t$ intron (Fu and Manley 1987; Fu et al. 1988). Thus, mutations in trans-acting factors that reduce the overall rate of splicing may have a more significant effect 
on splicing of a weakened intron such as small $t$ than on a more typical intron. It is likely, then, that some mutations that abolish small $t$ splicing do not necessarily identify bases essential for splicing but, rather, ones in which mutations can reduce the rate of the reaction. The picture that emerges from our studies may therefore reflect an ideal, or optimal, structure that can be somewhat plastic in many instances. This appears to be the case for other RNA-RNA interactions involved in splicing. For example, branch site and 5' splice site sequences in metazoa can be highly diverged from the consensus, and the U2-branch site and U6-5' splice site interactions envisioned for the "optimal" pre-mRNA would not occur. How such RNAs are spliced is unclear, but possibilities include redundancies in the RNA machinery and/or an especially important role for protein splicing factors.

Ohshima and colleagues (Tani and Ohshima 1991; Tani et al. 1992) noted a similarity between sequences in the central region of U6 snRNA and the catalytic domain of the negative strand of the satellite RNA of tobacco ring spot virus (the hairpin ribozyme). Our data provide support for the relevance of this similarity to the first step of pre-mRNA splicing. Specifically, the U2-U6 structure suggested by our data bears a striking similarity to the hairpin ribozyme bound to its substrate (see Fig. 8B; Hampel et al. 1990). U2-U6 helix III resembles the ribozyme helix 1, whereas elimination of U2-U6 he$\mathrm{lix} \mathrm{Ib}$ and incorporation of the relevant bases into the U6 intramolecular helix significantly increases the similarity of this helix with the corresponding regions of the hairpin ribozyme (i.e., helices 2 and 3; Fig. 8B). It is noteworthy that helix 1 of the ribozyme can be extended to a length of 10-12 bp (Hampel et al. 1990), which would result in a structure more closely resembling U2-U6 helix III. There is another helix in the viral RNA that is very similar to U2-U6 helix II, although it is not essential for activity of the ribozyme (for review, see Symons 1992). As noted previously (Tani and Ohshima 1991), there are also striking sequence similarities. The invariant ACAGAGA sequence in U6 is not only present in the hairpin ribozyme but in a similar position and configuration in each ( $5^{\prime}$ end paired, $3^{\prime}$ end unpaired). In both instances cleavage occurs immediately $5^{\prime}$ to a GU dinucleotide, with the $2^{\prime} \mathrm{OH}$ of an adenosine serving as the nucleophile. Finally, both reactions are transesterifications involving direct in-line $\mathrm{S}_{\mathrm{N}} 2$ displacement mechanisms (for review, see Symons 1992; Moore et al. 1993).

The above considerations support the significance of the U2/U6-hairpin ribozyme similarity. But there are also important differences that could argue against it. First, in the above model, U2 snRNA is equivalent to the substrate of the ribozyme; however, it is the pre-mRNA, not U2, that is cleaved during splicing. Second, as described in the introductory section, the chemistries of the reaction products are different. The following model for the first step of splicing incorporates the similarities with the hairpin ribozyme, but at the same time accommodates the differences in a novel U2-U6/pre-mRNA structure (Fig. $8 \mathrm{C}$ ). Cleavage by the ribozyme appears to involve activation of the $2^{\prime} \mathrm{OH}$ of an adenosine in the substrate RNA, which then attacks the adjacent phosphodiester bond (see Fig. 8B). In splicing, we suggest that the pre-mRNA is incorporated into the U2-U6 structure via interactions between the branch site and U2 and the $5^{\prime}$ splice site and U6. [U2 and U6 bases at the right end of helix III (U2 36-38 and U6 41-42) must pair with the pre-mRNA, not with each other (see Fig. 8A,C). As the U2-pre-mRNA interaction occurs before U2-U6 basepairing, it may be that this part of helix III does not form, or forms subsequently in the reaction, e.g., to expel the mRNA following splicing.] The U2-branch site interaction results in the well-known structure in which the branchpoint adenosine is bulged from a helix. As noted by Weiner (1993), the bulged A may be intercalated in the helix, but with the $2^{\prime} \mathrm{OH}$ on the surface. This could place the branchpoint adenosine in a similar position as the adenosine activated by the hairpin ribozyme (Fig. 8, cf. $\mathrm{B}$ and $\mathrm{Cl}$. We suggest that the $2^{\prime} \mathrm{OH}$ of the branchpoint adenosine is activated by a mechanism similar to that used by the hairpin ribozyme (perhaps involving a sequence or structure within the U6 intramolecular helix). However, in the geometry of the U2-U6/pre-mRNA complex, we suggest that the most accessible or reactive phosphodiester bond for attack is not the adjacent one in the pre-mRNA, but rather the $5^{\prime}$ splice site. Consistent with this, the $5^{\prime}$ splice site becomes directly juxtaposed with the branchpoint by the combined action of U2-U6 helices I and III and the U6-5' splice site and U2-branch site interactions (Fig. 8C). Nucleophilic attack by the activated $2^{\prime} \mathrm{OH}$ then results in cleavage at the $5^{\prime}$ splice site, producing the $5^{\prime}$ exon with a $3^{\prime} \mathrm{OH}$ and the lariat intron- $3^{\prime}$ exon.

We believe that the above model provides an attractive, albeit undoubtedly oversimplified, view of how the first step of splicing might occur. But perhaps conspicuous in its absence is mention of the equally attractive similarity with group II self-splicing RNAs. We conclude by speculating that a group II-like structure may become critical during the second step of splicing. Moore and Sharp (1993) provided elegant biochemical evidence that the catalytic centers for the two steps of splicing are not identical and suggested that a conformational change in the active site may occur between the two steps. They proposed that this could involve a switch from a group II-like structure to a group I-like structure. An alternative plausible scenario is that the switch is from the hairpin-like structure suggested by our data to a group II domain 5-like structure. This would involve (at least) melting of both the lower part of the U6 intramolecular stem and also the $U 2$ intramolecular stem, leading to formation of helix Ib. Although this model is speculative, it is not inconsistent with available data. For example, a number of U2 and U6 mutations with specific second step defects map at or near the junction of helices Ia and Ib (Fabrizio and Abelson 1990; Madhani and Guthrie 1992, 1994b; McPheeters and Abelson 1992; Wolff et al. 1994). However, the important conclusion from our work is that it provides a specific model for catalysis of the first step of splicing and thereby suggests a possible 
relationship between the complex pre-mRNA splicing machinery and a relatively simple viral ribozyme.

\section{Materials and methods}

\section{Plasmid constructions}

$\mathrm{U} 2$ and U6 mutants were constructed in pBluescript $\mathrm{SK}+(\mathrm{Wu}$ and Manley 1991). All the U2 constructs contain 556 bp of U2 $5^{\prime}$-flanking sequence. U6 constructs contain $470 \mathrm{bp}$ of $5^{\prime}$-flanking sequence, $106 \mathrm{bp}$ of coding sequence, and $220 \mathrm{bp}$ of $3^{\prime}$-flanking sequence. The single-stranded template for oligonucleotidedirected mutagenesis was prepared by superinfection with the helper phage M13K07 as described by the supplier (Bio-Rad). Oligonucleotide-directed mutagenesis was performed essentially as described previously, and mutants were identified by DNA sequencing. Double mutants in the U6 intramolecular helix that contain mutations on both sides of the stem were made by ligating a 536-bp HindIII-EcoNI fragment from the plasmid containing mutations at positions 54 and/or 55, with the 3260-bp EcoNI-HindIII fragment from the plasmid containing mutations at positions 80 and/or 81 . The mutant SV-GGU$5 \mathrm{C}$ was constructed by first subcloning the $N d e \mathrm{I}$ and BsmI fragment of SV-GGU into pBluescript SK + for mutagenesis. Mutated DNA was recloned into SV-GGU (Wu and Manley 1989) by ligating the mutated BstXI-PflMI fragment (SV40 nucleotides 4759-4558) together with PflMI-BamHI (SV40 nucleotides 4558-2533) and BamHI-BstXI (pBR322 nucleotide 375 to SV40 nucleotide 4759 ) fragments derived from SV-GGU. All U2 and U6 mutations in helix Ia, Ib, and the U2 and U6 intramolecular helices, as well as U2-A48G and U6-U31C, were constructed in the vectors of U2-UCA-7G and U6-91C as appropriate. All other U2 and U6 mutants (in helix III) were constructed in U6 wild-type and U2-UCA vectors.

\section{Transfection and RNA purification}

Human 293 cells were grown in Dulbecco's modified Eagle medium supplemented with $10 \%$ fetal bovine serum. Confluent cells were split 1:8 1 day before the addition of DNA precipitate. Cell transfections were performed as described (Wu and Manley 1989), except that $10 \mu \mathrm{g}$ of SV40 plasmid plus $10 \mu \mathrm{g}$ of the indicated U2 plasmid and $20 \mu \mathrm{g}$ of the indicated U6 plasmid were used in each sample. Transient expression was terminated $48 \mathrm{hr}$ after DNA addition, and cytoplasmic and nuclear RNAs were isolated essentially as described by Fu and Manley (1987). All experiments were repeated a minimum of three times, and in all cases but one the results obtained were essentially identical to those shown. The one exception was the apparent dominant-negative effect observed with certain U6 helix III mutations, which, as mentioned in the Results, was somewhat variable.

\section{S1 nuclease analysis}

S1 nuclease analysis was performed essentially as described (Wu and Manley 1992), with a 3'-end-labeled HindIII-BsmI DNA probe (nucleotide 5171-4528) isolated from SV-WT. The use of this probe permitted resolution of unspliced pre-mRNA and undigested probe when SV-AGU was use in transfections. Briefly, $60 \mu \mathrm{g}$ of cytoplasmic RNA was hybridized with $10 \mathrm{ng}$ of denatured double-stranded DNA probe at $43^{\circ} \mathrm{C}$ overnight. S1 nuclease digestion was performed at $37^{\circ} \mathrm{C}$ for $1 \mathrm{hr}$ with 150 units of S1 nuclease (Sigma). S1 nuclease-resistant products were resolved by electrophoresis through $5 \%$ polyacrylamide $-7 \mathrm{M}$ urea gels, which were dried and exposed to X-ray film at $-70^{\circ} \mathrm{C}$ in the presence of intensifying screens. Most gels were also quantitated by PhosphorImager analysis (Molecular Dynamics).

\section{Acknowledgments}

We are grateful to J. Wu and J. Wang for advice and helpful discussions and to L. Zhong for technical assistance. This work was supported by National Institutes of Health grant GM 48259.

The publication costs of this article were defrayed in part by payment of page charges. This article must therefore be hereby marked "advertisement" in accordance with 18 USC section 1734 solely to indicate this fact.

\section{References}

Brow, D.A. and C. Guthrie. 1989. Splicing a spliceosomal RNA. Nature 337: 14-15.

Cech, T.R. 1986. The generality of self-splicing RNA: Relationship to nuclear mRNA splicing. Cell 44: 207-210.

Cortes, J.J., E.J. Sontheimer, S.D. Seiwert, and J.A. Steitz. 1993. Mutations in the conserved loop of human U5 snRNA generate use of novel cryptic $5^{\prime}$ splice sites in vivo. EMBO $J$. 12: $5181-5189$.

Datta, B. and A.M. Weiner. 1991. Genetic evidence for base pairing between $\mathrm{U} 2$ and $\mathrm{U} 6$ snRNAs in mammalian mRNA splicing. Nature 352: 821-824.

. 1993. The phylogenetically invariant ACAGAGA and AGC sequences of U6 small nuclear RNA are more tolerant of mutation in human cells than in Saccharomyces cerevisiae. Mol. Cell. Biol. 13: 5377-5382.

Fabrizio, P. and J. Abelson. 1990. Two domains of yeast U6 small nuclear RNA required for both steps of nuclear precursor messenger RNA splicing. Science 250: 404-409.

Fortner, D.M., R.G. Troy, and D.A. Brow. 1994. A stem/loop in U6 RNA defines a conformational switch required for premRNA splicing. Genes \& Dev. 8: 221-233.

Fu, X.-Y. and J.L. Manley. 1987. Factors influencing alternative splice site utilization in vivo. Mol. Cell. Biol. 7: 738-748.

Fu, X.-Y., J. Colgan, and J.L. Manley. 1988. Multiple cis-acting sequence elements are required for efficient splicing of $\mathrm{SV} 40$ small t pre-mRNA. Mol. Cell. Biol. 8: 3582-3590.

Green, M.R. 1991. Biochemical mechanisms of constitutive and regulated pre-mRNA splicing. Annu. Rev. Cell Biol. 7: 559599.

Guthrie, C. 1991. Messenger RNA splicing in yeast: Clues to why the spliceosome is a ribonucleoprotein. Science 253: $157-163$.

Guthrie, C. and B. Patterson. 1988. Spliceosomal snRNAs. Annu. Rev. Genet. 22: 387-419.

Hampel, A., R. Tritz, M. Hicks, and P. Cruz. 1990. Hairpin catalytic RNA model: Evidence for helices and sequence requirement for substrate RNA. Nucleic Acids Res. 18: 299304.

Hausner, T.-P., L.M. Giglio, and A.M. Weiner. 1990. Evidence for base-pairing between mammalian U2 and U6 small nuclear ribonuleoprotein particles. Genes \& Dev. 4:21462156.

Kandels-Lewis, S. and B. Seraphin. 1993. Role of U6 snRNA in 5' splice site selection. Science 262: 2035-2039.

Konforti, B.B., M.J. Koziolkiewicz, and M.M. Konarska. 1993. Disruption of base pairing between the $5^{\prime}$ splice site and the $5^{\prime}$ end of U1 snRNA is required for spliceosome assembly. Cell 75: 863-873.

Lamond, A.I., M.M. Konarska, P.J. Grabowski, and P.A. Sharp. 
1988. Spliceosome assembly involves the binding and release of U4 small nuclear ribonucleoprotein. Proc. Natl. Acad. Sci. 85: 411-415.

Lesser, C.F. and C. Guthrie. 1993. Mutations in U6 snRNA that alter splice site specificity: Implications for the active site. Science 262: 1982-1988.

Madhani, H.D. and C. Guthrie. 1992. A novel base-pairing interaction between $\mathrm{U} 2$ and U6 snRNAs suggests a mechanism for the catalytic activation of the spliceosome. Cell 71: 803-817.

-1994a. Dynamic RNA-RNA interactions in the spliceosome. Annu. Rev. Genet. 28: 1-26.

- 1994b. Randomization-selection analysis of snRNAs in vivo: Evidence for a tertiary interaction in the spliceosome. Genes \& Dev. 8: 1071-1086.

Madhani, H.D., R. Bordonne, and C. Guthrie. 1990. Multiple roles for U6 snRNA in the splicing pathway. Genes \& Dev. 4: 2264-2277.

McPheeters, D.S. and J. Abelson. 1992. Mutational analysis of the yeast U2 snRNA suggests a structural similarity to the catalytic core of group I introns. Cell 71: 819-831.

Michel, F., R. Umesono, and H. Ozeki. 1989. Comparative and functional anatomy of Group II catalytic introns. Gene 82: 5-30.

Moore, M.J. and P.A. Sharp. 1993. Evidence for two active sites in the spliceosome provided by stereochemistry of premRNA splicing. Nature 365: 364-368.

Moore, M.J., C.C. Query, and P.A. Sharp. 1993. Splicing of precursors to mRNA by the spliceosome. In The RNA world led. J. Atkins and R. Gesteland), pp. 303-357. Cold Spring Harbor Laboratory Press, Cold Spring Harbor, New York.

Newman, A.J. and C. Norman. 1991. Mutations in yeast U5 snRNA alter the specificity of $5^{\prime}$ splice-site cleavage. Cell 65: 115-123.

- 1992. U5 snRNA interacts with exon sequences at $5^{\prime}$ and 3' splice sites. Cell 68: 743-754.

Nilsen, T.W. 1994. RNA-RNA interactions in the spliceosome: Unraveling the ties that bind. Cell 78: $1-4$.

Noble, J.C.S., Z.-Q. Pan, C. Prives, and J.L. Manley. 1987. Splicing of SV40 early pre-mRNA to large $T$ and small $t$ mRNAs utilizes different pattern of lariat branch sites. Cell 50: 227 236.

Noble, J.C.S., C. Prives, and J.L. Manley. 1988. Alternative splicing of SV40 early pre-mRNA is determined by branch site selection. Genes \& Dev. 2: 1460-1475.

Parker, R., P.G. Siliciano, and C. Guthrie. 1987. Recognition of the TACTAAC box during mRNA splicing in yeast involves base pairing to the U2-like snRNA. Cell 49: 229-239.

Sawa, H. and J. Abelson. 1992. Evidence for a base-pairing interaction between U6 small nuclear RNA and 5' splice site during the splicing reaction in yeast. Proc. Natl. Acad. Sci. 89: 11269-11273.

Sawa, H. and Y. Shimura. 1992. Association of U6 snRNA with the $5^{\prime}$-splice site region of pre-mRNA in the spliceosome. Genes \& Dev. 6: 244-254.

Seraphin, B., L. Kretzner, and M. Rosbash. 1988. A U1 snRNA: Pre-mRNA base pairing interaction is required early in spliceosome assembly but does not uniquely define the $5^{\prime}$ cleavage site. $E M B O$ /. 7: 2533-2538.

Shannon, K.W. and C. Guthrie. 1991. Suppressors of a U4 snRNA mutation define a novel U6 snRNP protein with RNA-binding motifs. Genes \& Dev. 5: 773-785.

Sharp, P.A. 1985. On the origins of RNA splicing and introns. Cell 42: 397-400.

- 1994. Split genes and RNA splicing. Cell 77: 805-815.

Siliciano, P.G. and C. Guthrie. 1988. 5' Splice site selection in yeast: Genetic alterations in base pairing with U1 reveal additional requirements. Genes \& Dev. 2: 1258-1267.

Sontheimer, E. and J.A. Steitz. 1993. The U5 and U6 small nuclear RNAs as active site components of the spliceosome. Science 262: 1989-1996.

Symons, R.H. 1992. Small catalytic RNAs. Annu. Rev. Biochem. 61: 641-671.

Takahashi, Y., S. Urushiyama, T. Tani, and Y. Ohshima. 1993. An mRNA-type intron is present in the Rhodotorula hasegawae U2 small nuclear RNA gene. Mol. Cell. Biol. 13: 56135619.

Tani, Y. and Y. Ohshima. 1989. The gene for the U6 small nuclear RNA in fission yeast has an intron. Nature 337: 87-90.

1991. mRNA-type introns in U6 small nuclear RNA genes: Implications for the catalysis in the pre-mRNA splicing. Genes \& Dev. 5: 1022-1031.

Tani, T., Y. Takahashi, and Y. Ohshima. 1992. Activity of chimeric RNAs of U6 snRNA and / - |sTRSV in the cleavage of a substrate RNA. Nucleic Acids Res. 20: 2991-2996.

Vankan, P., C. McGuigan, and I.W. Mattaj. 1992. Roles of U4 and U6 snRNAs in the assembly of splicing complexes. EMBO \%. 11: 335-343.

Wassarman, D.A. and J.A. Steitz. 1992. Interactions of small nuclear RNA's with precursor messenger RNA during in vitro splicing. Science 257: 1918-1925.

Weiner, A.M. 1993. mRNA splicing and autocatalytic introns: Distant cousins or the products of chemical determinism? Cell 72: 161-164.

Wolff, T. and A. Bindereif. 1992. Reconstituted mammalian U4/ U6 snRNP complements splicing: A mutational analysis. EMBO J. 11: 345-359.

- 1993. Conformational changes of U6 RNA during the spliceosome cycle: An intramolecular helix is essential both for initiating the U4-U6 interaction and for the first step of splicing. Genes \& Dev. 7: 1377-1389.

Wolff, T., R. Menssen, J. Hammel, and A. Bindereif. 1994. Splicing function of mammalian U6 small nuclear RNA: Conserved positions in central domain and helix I are essential during the first and second step of pre-mRNA splicing. Proc. Natl. Acad. Sci. 91: 903-907.

Wyatt, J.R., E.J. Sontheimer, and J.A. Steitz. 1992. Site-specific cross-linking of mammalian U5 snRNP to the $5^{\prime}$ splice site before the first step of pre-mRNA splicing. Genes \& Dev. 6: $2542-2553$

Wu, J. and J.L. Manley. 1989. Mammalian pre-mRNA branch site selection by U2 snRNP involves base-pairing. Genes \& Dev. 3: 1553-1561.

1991. Base-pairing between U2 and U6 snRNAs is necessary for splicing of a mammlian pre-mRNA. Nature 352: 818-821.

- 1992. Multiple functional domains of human U2 small nuclear RNA: Strengthening conserved Stem I can block splicing. Mol. Cell. Biol. 12: 5464-5473.

Yean, S.-L. and R.-J. Lin. 1991. U4 small nuclear RNA dissociates from a yeast spliceosome and does not participate in the subsequent splicing reaction. Mol. Cell. Biol. 11: 5571-5577.

Yu, Y.-T., P.A. Maroney, and T.W. Nilsen. 1993. Functional reconstitution of U6 snRNA in nematode cis- and transsplicing: U6 can serve as both a branch acceptor and a 5' exon. Cell 75: 1049-1060.

Zhuang, Y. and A.M. Weiner. 1986. A compensatory base change in U1 snRNA suppresses a $5^{\prime}$ splice site mutation. Cell 46: 827-835.

1989. A compensatory base change in human U2 snRNA can suppress a branch site mutation. Genes \& Dev. 3: $1545-1552$. 


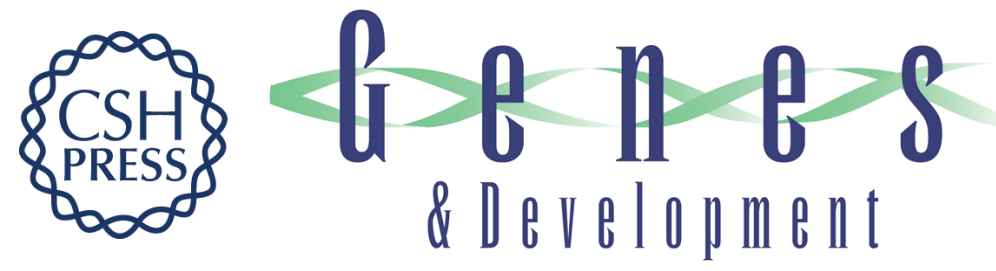

\section{A novel U2-U6 snRNA structure is necessary for mammalian mRNA splicing.}

J S Sun and J L Manley

Genes Dev. 1995, 9:

Access the most recent version at doi:10.1101/gad.9.7.843

References This article cites 58 articles, 28 of which can be accessed free at:

http://genesdev.cshlp.org/content/9/7/843.full.html\#ref-list-1

License

Email Alerting

Service

Receive free email alerts when new articles cite this article - sign up in the box at the top right corner of the article or click here.

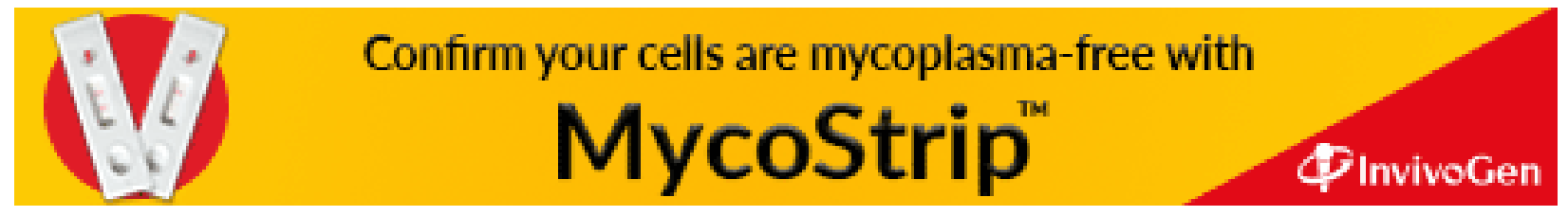

